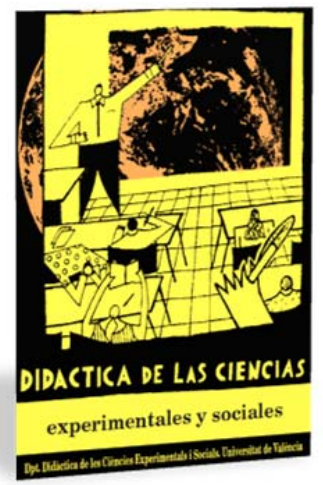

\title{
Pensar la ciudad global desde sus representaciones escolares: un estudio de caso entre Valencia (España) y Bogotá (Colombia)
}

\author{
Focusing on the global city from school \\ representations: a case study among Valencia \\ (Spain) and Bogotá (Colombia)
}

DOI: $10.7203 / D C E S .34 .12182$

\author{
Diego García Monteagudo \\ Universitat de València. Proyecto Gea-Clío \\ diego.garcia@uv.es \\ Luis Guillermo Torres Pérez \\ Universidad Pedagógica Nacional (Bogotá, Colombia). Grupo Geopaideia \\ luguitope@gmail.com
}

\begin{abstract}
RESUMEN: Las concepciones del espacio urbano del alumnado de Educación Secundaria de varios centros de Valencia y Bogotá nos aproximan a la representación escolar de la ciudad global. La relación entre las representaciones sociales y la geografía de la percepción y del comportamiento nos revela que el alumnado construye unas ideas sobre el espacio urbano inmediato en el seno de la comunidad social a la que pertenece. La movilidad, las relaciones sociales y el apego por el espacio urbano inmediato son aspectos disímiles en ambas ciudades, pero nos conducen a afirmar la necesidad de potenciar estrategias de enseñanza que incluyan el espacio vivido y la escala local para afrontar el aprendizaje de la ciudad global.
\end{abstract}

Palabras Clave: espacio urbano, Educación Secundaria, representaciones sociales, espacio vivido, ciudad global.

ABSTRACT: The conceptions of the urban space of Secondary Education students of several centres of Valencia and Bogotá approach us to the school representation of the global city. The relationship between social representations and the geography of perception and behaviour reveals that students build ideas about the immediate urban space within the social community to which they belong. Mobility, social relations and attachment to the immediate urban space are dissimilar aspects in both cities, but they lead us to affirm the need to strengthen teaching strategies that include the lived space and the local scale to face the learning of the global city.

KEYWORDS: Urban Space, Secondary Education, Social Representations, Lived space, Global City.

Fecha de recepción: marzo de 2018 Fecha de aceptación: mayo de 2018

El presente artículo forma parte del proyecto Interuniversitario "Competencias sociales para una ciudadanía democrática: análisis, desarrollo y evaluación” (COMDEMO-EDU2015-65621-C3-1-R) y del proyecto de investigación "Semiótica del espacio, construcciones de sentido a través de la fotografía”, adscrito al Doctorado Interinstitucional de Educación de la Universidad Pedagógica Nacional de Colombia, en la línea Lenguaje y Educación. 


\section{INTRODUCCIÓN}

Hace aproximadamente dos años que se publicó el informe Ciudades Globales 2030, un estudio comparativo que aglutina información sobre 750 ciudades del planeta (57 \% del PIB mundial) y proyecta las condiciones de vida mundiales en los próximos quince años. En ese momento advertimos que cualquier investigación didáctica sobre el espacio urbano a escala global tenía que atender la emergencia de ciudades de América Latina (Sao Paulo, Buenos Aires, Bogotá...). Ante esta premisa hemos aprovechado los trabajos de Souto (1998) y Rodríguez (2010) para seguir reflexionando sobre los procesos educativos del espacio geográfico, en concreto, acerca de la ciudad global. Nuestro entendimiento de la ciudad global como espacio donde se localizan los procesos de globalización (Sassen, 1991) nos ha llevado a revisar publicaciones científicas que hayan abordado el medio urbano o la ciudad desde un enfoque escolar. Así lo han hecho González y García Pérez (2014) como síntesis de una tesis doctoral en la que han defendido el medio urbano como ámbito de conocimiento escolar con alumnos de Educación Secundaria en Bogotá. En el caso de Valencia tenemos el estudio de Morales Yago (2015) con estudiantes universitarios. Con este pretexto queremos conocer las representaciones sociales de la ciudad global desde la escala local, pues consideramos que el conocimiento sobre cómo se aprende en/de las ciudades de Valencia y Bogotá (son entornos que ofrecen contenidos geográficos) permiten formar una representación social de la ciudad global como contenido educativo que será de utilidad para mejorar la participación pública del alumnado en los asuntos urbanos.

En consecuencia hemos planteado esta investigación comparativa bajo el enfoque comprensivo de la teoría de las representaciones sociales, ya que nuestra conjetura inicial señala que la percepción geográfica sobre la ciudad global está condicionada por el contexto social que tiene un reflejo visible en el espacio complejo que se estudia desde la geografía de la percepción y del comportamiento. El espacio complejo que constituye la ciudad global en este trabajo es bastante semejante al ámbito de las representaciones sociales, pues las ideas sobre la ciudad global y el espacio urbano (local) se construyen en el seno de un contexto social. Nuestro propósito principal es averiguar cómo esas ideas que forman estudiantes de Educación Secundaria de Valencia (dos centros educativos) y Bogotá (un centro educativo) para comprender el espacio urbano inmediato les sirven para explicar el concepto de ciudad global. Como esa valoración del espacio urbano tiene en cuenta fuentes de información diversas (familiares, amigos, los/las docentes, medios de comunicación, redes sociales...) y afecta a la movilidad del alumnado hemos relacionado las representaciones sociales con la escuela de la percepción y del comportamiento.

\section{APUESTAS EDUCATIVAS A PARTIR DE LAS REPRESENTACIONES SOCIALES DEL ESPACIO URBANO}

Las ciudades se vinculan entre sí a partir de redes técnicas, institucionales y de personas, además de la propia división espacial del trabajo, que afectan a la calidad y variedad de funciones en las que se van especializando y que terminan definiendo un rango o posición a escala mundial. Este entendimiento del espacio urbano como sistema nos ayuda en los procesos de enseñanza y aprendizaje de la ciudad si, por ende, somos capaces de mostrar los contrastes territoriales que se vienen desarrollando como resultado de los procesos de globalización. A diferentes escalas (global, regional, local) emergen diferencias en las condiciones de vida de los habitantes urbanos que son apreciables en elementos socioeconómicos, características étnicas y culturales, así como en el propio paisaje.

La asunción de unos presupuestos activos en la construcción social del conocimiento es la base de la formulación teórica de Serge Moscovici (1979) y desde la cual se entiende que el conocimiento sobre la realidad social es un fenómeno complejo que se genera en determinadas circunstancias y dinámicas, cuya construcción viene determinada por las relaciones sociales y 
culturales. Con esta premisa nuestra hipótesis señala que las representaciones escolares acerca del espacio urbano están relacionadas con una visión de sentido común que es aceptada en su comportamiento diario (movilidad de casa al instituto, visitas y reuniones con familiares y amigos, práctica de actividades al aire libre...). Son representaciones sociales porque se insertan en su hábito de recorrer las calles y barrios de Valencia y Bogotá, y afecta a su comportamiento a la hora de desplazarse y tomar decisiones sobre la elección de determinados itinerarios.

A partir de estas representaciones escolares nos aproximaremos a conocer las ideas que explican el concepto de ciudad global, cuyos imaginarios escapan al espacio concebido por las administraciones públicas en su quehacer político y jurídico. El conocimiento de los estudiantes sobre su espacio vivido (el parque donde se reúnen al salir de clase, el campo de fútbol, un edificio emblemático...) actúa como un principio interpretativo y orientador de su práctica espacial (espacio percibido) que explican a partir de códigos y valores que asumen dentro de un marco cultural de referencia. A diferencia del filtro que constituye el espacio percibido en el imaginario de las personas, el espacio vivido ha sido configurado en la mente de los estudiantes como una realidad ordenada y objetivada a partir de visiones individuales que se han conformado en el contexto de una comunidad social.

La influencia que ejerce el medio cultural en la percepción social del espacio refuerza la vinculación entre la teoría de las representaciones sociales y la Geografía de la Percepción y del Comportamiento bajo el enfoque del constructivismo. De hecho, el constructivismo social permite conocer el comportamiento humano a partir de las representaciones sociales, ya que el estímulo que provoca el objeto de una representación social (en este caso el espacio urbano) justifica una determinada respuesta de acuerdo a una representación social que describe ese objeto de manera inteligible para cada persona, lo que genera una actividad que se acaba proyectando en el espacio (Sammut, Andreouli, Gaskell y Valsiner, 2015). Estas evidencias deben considerarse desde un ámbito grupal para fomentar estrategias de enseñanza conjuntas en los centros educativos acerca de temáticas concretas, como en este caso defendemos para el aprendizaje de la ciudad global.

El carácter social de las representaciones sobre el espacio urbano que tienen los estudiantes de Valencia y Bogotá viene dado por una determinación bidireccional en constante interacción y reconstrucción. Por un lado, una determinación social a nivel macro que hace referencia a la cultura global en la que los estudiantes se ven insertos en el momento actual en el que hemos desarrollado la investigación. Es precisamente este carácter del pensamiento global el que nos ha permitido realizar comparaciones entre las representaciones sociales del espacio urbano del alumnado de Valencia y Bogotá. Y por otro lado, porque cada grupo de estudiantes pertenece a un colectivo social (IES Ramón Llull y IES Fuente de San Luís en Valencia, y Colegio General Santander IED en Bogotá) dentro de la comunidad escolar a la que pertenecen. Este contexto local imprime una manera de concebir el barrio y la ciudad en cada grupo de estudiantes, lo que nos facilita la interpretación grupal de los datos en cada una de las ciudades de estudio.

Desde esta aplicación didáctica de la teoría de las representaciones sociales junto con la geografía de la percepción y del comportamiento, se han realizado estudios concretos desde que esta corriente se difundió en España a partir del artículo seminal del profesor Horacio Capel (1973) y de las traducciones de obras de Bailly y Lynch (Vara, 2008). En la década de 1980, se fue afianzando esta corriente empleando encuestas y mapas cognitivos para conocer la percepción urbana. Una década más tarde, los estudios de los profesores Boira, Reques y Souto (1994), así como los de Fernández Gutiérrez y Asenjo Pelegrina (1998) marcaron el punto de madurez y sentaron las bases para extender este enfoque a otras áreas temáticas (geografía del ocio, del tiempo, del turismo, de los centros comerciales...etc.). Progresivamente las investigaciones han ido afianzándose con un enfoque interdisciplinar y la combinación de técnicas como encuestas, mapas mentales, entrevistas y análisis de textos, que se han ido sintetizando por Castro (1997).

En el caso de Bogotá se tiene en cuenta la tesis doctoral de J. Francisco González cuyos resultados principales se han publicado en la revista Didáctica Geográfica (González y García 
Pérez, 2014). En la investigación se han manejado cuatro categorías (problemas urbanos, espacio público, participación ciudadana y calidad de vida) sobre las que se exponen las principales concepciones y cómo se puede evolucionar en sentido ascendente hasta alcanzar el nivel máximo de interrelación de elementos urbanos para comprender la ciudad como un sistema urbano complejo.

\section{EL PROCESO METODOLÓGICO: ENFOQUE COMPARATIVO, TÉCNICAS Y CONTEXTO ESPACIAL}

El carácter didáctico nos obliga a dotar a este trabajo de un método de carácter comparativo y una metodología de orientación comprensiva que se vincula con una perspectiva holística conduciéndonos a averiguar cuáles son las concepciones sociales de los estudiantes de Educación Secundaria acerca del espacio urbano. Ese conocimiento ha sido construido por el alumnado durante su vida, combinándose sus vivencias como ciudadanos y sus experiencias como estudiantes. Por tanto, sus representaciones sociales reflejarán sus motivaciones, sus intereses y sentimientos acerca de los espacios urbanos (sendas, hitos, bordes...) que consideran como referentes en sus imágenes mentales, y que mostrarán mediante sus explicaciones en la encuesta (Anexo I).

La selección de la muestra de estudiantes ha sido intencional y se ha basado en la disposición docente para recopilar datos, aunque es conveniente precisar algunas diferenciaciones sociales y económicas entre los distritos ${ }^{1}$. En el caso de Valencia, los centros de Educación Secundaria se ubican en los distritos de Algirós (IES Ramón Llull) y Quatre Carreres (IES Fuente de San Luís) (Imagen 1). El primero (37.043 habitantes en 2017) es una prolongación hacia el este del distrito limítrofe (El Pla del Reial), lo que explica que sea el cuarto con el precio más elevado del suelo. Esto se debe fundamentalmente a la construcción del campus universitario de ciencias sociales (Tarongers) de la Universidad de Valencia y las vías de comunicación con las playas de la Malva Rosa y el puerto de Valencia. Por el contrario la proximidad de la Ciudad de las Artes y las Ciencias, así como del Jardín del Turia no desempeñan un papel de revalorización económica debido a la gran extensión de segundo distrito que cuenta con 73.769 habitantes (en 2017). De hecho, el predominio de familias gitanas e inmigrantes residentes en los polígonos de viviendas de la Avenida de La Plata (a escasos metros del IES Fuente de San Luís) actúan como un obstáculo a la instalación de familias españolas de clase media en la mayor parte de Quatre Carreres. En ambos distritos, la inmigración es fundamentalmente europea (UE-28) y de América Latina con unas proporciones que ronda el 6 y el $8 \%$. Sin embargo, las opiniones del alumnado atribuyen las malas conductas de sus barrios al colectivo inmigrante, llegándose a denunciar la apropiación casi exclusiva de algunos espacios (sobre todo parques) por parte de ellos y ellas.

En cuanto a la institución educativa en la cual se desarrollo la encuesta en Bogotá (Colegio General Santander IED), se encuentra ubicada en la localidad de Usaquén ${ }^{2}$ al noreste de la ciudad (Imagen 2). Esta localidad cuenta con una población de 449.621 habitantes (año 2016) y una extensión territorial aproximada de 6.500 hectáreas. Esta gran extensión marca la diferencia entre un centro más desarrollado económicamente y arquitectónicamente, y una periferia que experimenta problemas de servicios básicos e inseguridad ciudadana. A nivel educativo es una de las localidades con mayor presencia de centros educativos en todos sus niveles (primaria, secundaria y universitaria) contando con instituciones públicas y privadas. El Colegio General Santander IED es una institución pública que ofrece educación desde Educación Primaria hasta Bachillerato. El alumnado que asiste al centro pertenece al barrio de Altablanca, que ha pasado de

\footnotetext{
${ }^{1}$ El distrito en la ciudad de Valencia es un territorio delimitado jurídicamente que agrupa a diferentes barrios. Hemos escogido esta demarcación porque un distrito urbano de Valencia equivale en extensión a los barrios de la ciudad de Bogotá.

${ }^{2}$ Las localidades en Colombia son divisiones administrativas propias de las ciudades que poseen una relativa homogeneidad en sus aspectos geográficos, culturales, sociales y económicos. En la ciudad de Bogotá existen 20 localidades divididas en varias Unidades de Planeamiento Zonal (UPZ) conformadas por barrios.
} 
ser un barrio obrero a acoger una diversidad de población principalmente originaria del departamento de Boyacá. Este barrio es de carácter residencial y alberga establecimientos comerciales de pequeña y mediana escala como corresponde a su clasificación entre los estratos 1 y $3^{3}$. Aunque está próximo a nodos de desarrollo financiero, la penetración de grupos sociales periféricos genera problemas relacionadas con las pandillas y el microtráfico.

IMAGEN 1. Localización de los centros de Educación Secundaria en Valencia

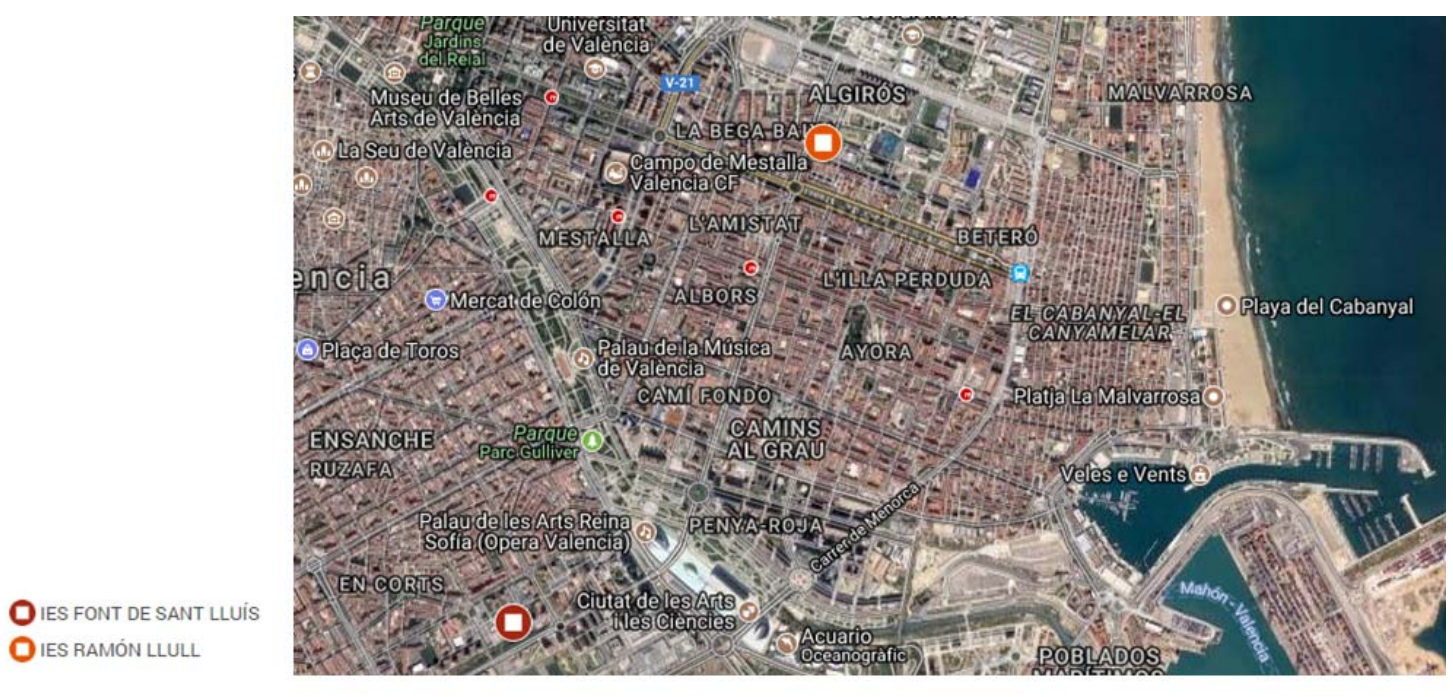

Fuente: Imágenes de Google Earth

IMAGEN 2. Localización de los centros de Educación Secundaria en Bogotá

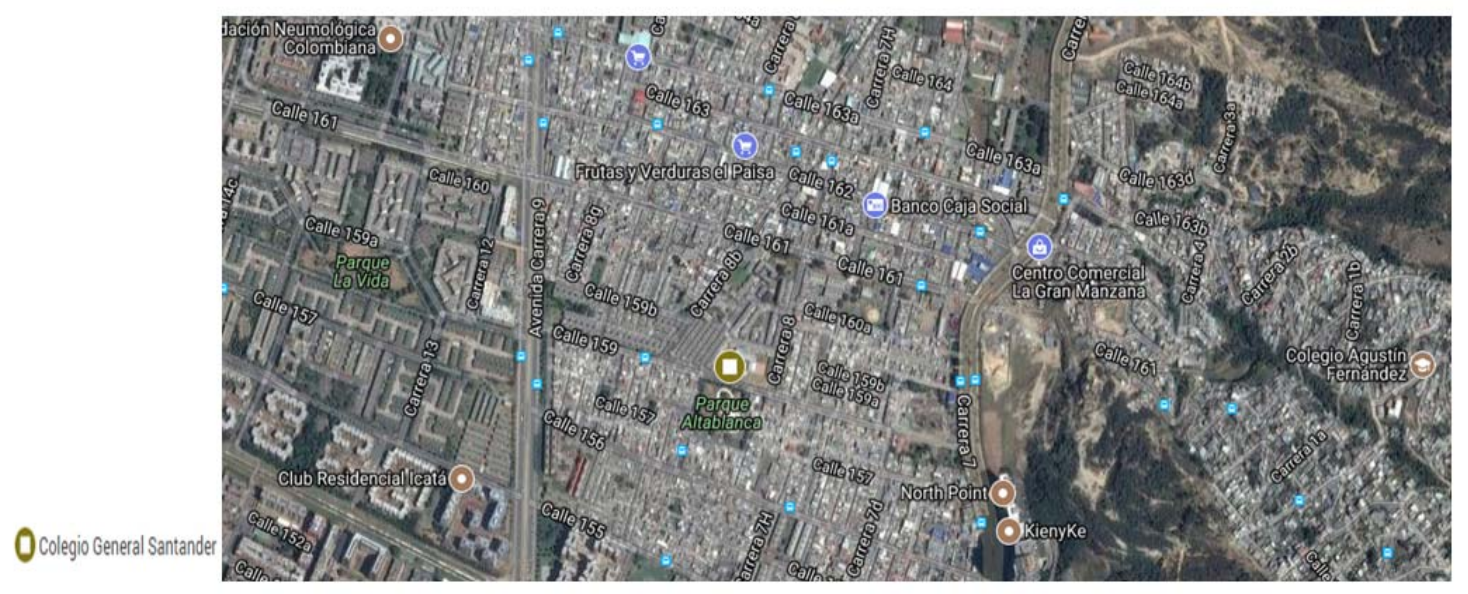

Fuente: Imágenes de Google Earth

\section{RESUlTAdOS: VALENCIA Y BOGOTÁ A PARTIR DE LA REPRESENTACIÓN SOCIAL DE LA POBLACIÓN ESCOLAR}

En las representaciones sociales de los estudiantes, los conocimientos escolares desempeñan una función primordial que hemos querido averiguar a partir del conocimiento de las ideas que poseen sobre los centros educativos, el barrio y la ciudad. Los centros educativos son el contexto

\footnotetext{
${ }^{3}$ Los estratos son una clasificación de los inmuebles residenciales que expresa el modo de vida socioeconómico y determina que sectores deben recibir servicios públicos. Son seis niveles (1 más bajo y el 6 más elevado), por lo que Altablanca se mueve entre un estrato bajo-bajo (estrato 1) a un medio-bajo (estrato 3).
} 
escolar de referencia desde el que se proyectan imágenes de los otros dos espacios en cuyos resultados hemos prestado atención a los aspectos valorativos y preferenciales.

\section{Valencia}

El primer elemento sobre el que ofrecemos una explicación valorativa concierne a la trama urbana (calles, avenidas y barrios). La percepción que tiene el alumnado de Valencia sobre estos elementos morfológicos nos ha permitido clasificar la información en sendas y bordes. Las sendas son las vías de comunicación o arterias principales del barrio que frecuentan en su desplazamiento cotidiano. Las principales sendas citadas han sido vías de primer orden dentro de la ciudad de Valencia como las Avenidas de Blasco Ibáñez y la Avenida del Puerto, y otras que cruzan transversalmente algunos barrios como la Avenida Reino de Valencia y Jacinto Benavente, esta última por ser paralela a varios tramos del Jardín del Turia. La representación de estas vías es positiva como corresponde a espacios que frecuentan regularmente.

Sobre la Avenida del Puerto han mencionado que "es una avenida muy viva” en relación al tráfico y la concurrencia de personas a lo largo del día, mientras que las recomendaciones que efectúan sobre las avenidas de Jacinto Benavente y Reino de Valencia esconden el deseo de disfrutar de zonas más verdes (de la primera han dicho que "está a la orilla del río y es agradable”), y tranquilas ("es una avenida con poco tráfico y jardines”) en el caso de la segunda. Otro grupo de estudiantes se ha referido a las sendas a partir de referencias más generales a escala de barrio, destacándose la vida cultural del barrio de Ruzafa.

Por el contrario, existe una representación negativa de ciertas avenidas (La Plata y la calle Zapadores) y barrios de la misma ciudad de Valencia. Las opiniones reflejan los prejuicios y estereotipos sobre estos espacios al referirse a la Plata en términos de "es una zona bastante peligrosa” y "no es un buen barrio". Pero cuando estos bordes forman parte de su espacio vivido sus representaciones sociales son más concretas y mencionan que la calle Zapadores "es mi calle y no la recomiendo pasar por la noche”, además de denunciar problemas específicos porque son calles que "suelen estar sucias y allí se acumula comida y botellones”. El barrio de El Cabanyal también representa un espacio peligroso para uno de los estudiantes del IES Ramón Llull. Aunque tan solo sea una opinión aislada, es digno señalar que los estudiantes de este centro están inmersos en el debate público sobre la prolongación de la Avenida Blasco Ibáñez hasta el mar o la conservación de este barrio.

En segundo lugar, los parques y jardines urbanos han sido los lugares más citados por los estudiantes. Estos espacios son nodos o puntos estratégicos en los que concentran buena parte de su actividad y encierran valores simbólicos que han expresado en sus respuestas. En esta categoría se han registrado dos jardines (Jardín del Turia y Viveros), seis parques y la Estación de ferrocarril de El Cabanyal.

El nodo más representativo ha sido el Jardín del Turia. Es el jardín urbano más grande de la ciudad de Valencia (9 kilómetros de longitud de oeste a este), que toma el nombre del antiguo lecho del río en el que fue construido en 1986. En su interior alberga el ambiente de paisaje fluvial mediterráneo con diferentes especies autóctonas, además de otras zonas deportivas y lúdicas. El jardín está interrumpido por dieciocho puentes transversales de diferentes épocas históricas y desde su lecho se da acceso a otros espacios como el Palau de la Música, la Ciudad de las Artes y las Ciencias, el parque de Gulliver, el Museo de Bellas Artes, el Bioparc y el Parque de Cabecera, entre los más destacados.

En la mayoría de los casos, los usos escolares del Jardín del Turia forman parte del espacio vivido que experimentan en su tiempo libre o de ocio. Las explicaciones escolares sobre este espacio se pueden sintetizar en tres modelos: una representación idílica que remarca la función de jardín natural, el desarrollo de actividades diversas y la concepción de espacio patrimonial que lo relaciona con edificios emblemáticos de la ciudad. A modo de ejemplo citamos la expresión de un 
alumno que remarca el carácter idílico del jardín diciendo que "es un lugar muy bonito y puedes estar en contacto con la naturaleza” y “es muy agradable y siempre hay buen ambiente”.

A diferencia del Jardín del Turia, los otros parques urbanos no forman parte de esa imagen de marca de la ciudad de Valencia publicitada en folletos turísticos y páginas webs. Se trata de parques de menor entidad y constituyen las únicas zonas verdes de algunos barrios que frecuenta el alumnado regularmente. Algunos como el Parque de Colores y el Jardín de Ayora son valorados positivamente por los estudiantes; sin embargo, los parques de Mortadelo y Filemón (al inicio de la Avenida Hermanos Maristas) y Blanqueríes quedan representados como espacios de rechazo (topofobia). En efecto, la percepción general de los parques por la población escolar denuncia la falta de un mantenimiento continuado mencionándose que "los parques del barrio están muy sucios” y "no los mantienen bien y muchos están abandonados, la gente que se reúne allí no es muy legal”.

El tercer elemento han sido los hitos urbanos. Estos puntos de referencia o guía en su quehacer diario estructuran sus desplazamientos por el barrio si forman parte de su espacio vivido, o reproducen una imagen hegemónica de la ciudad de Valencia al coincidir con un espacio concebido por la administración pública. La variedad de respuestas se puede sintetizar en cuatro bloques. Si dejamos de lado la diversidad de hitos urbanos relacionados con el ocio (bares, restaurantes, tiendas de videojuegos...), los servicios deportivos son los que desempeñan una función primordial en el imaginario de los estudiantes. El estadio de fútbol (Mestalla) y las canchas de fútbol y baloncesto que existen en los diferentes barrios son los elementos más nombrados por el alumnado de los dos centros. En cuanto a los servicios educativos, la proximidad geográfica del alumnado del IES Ramón Llull ha sido un acicate para citar el campus de Tarongers y la facultad de Medicina, mientras que los del otro centro han señalado la biblioteca municipal. De un modo similar, el factor proximidad ha influido a la hora de recomendar visitas a los servicios de bomberos y policía entre los alumnos del IES Fuente de San Luís, y esté último junto con los servicios judiciales en el otro centro. En el anexo II hemos mostrado un mapa con los lugares preferidos por un grupo de alumnos/as del IES Ramón Llull que coincide con la mayoría del alumnado de Valencia.

\section{Bogotá}

En el caso de Bogotá, la mayor extensión de la ciudad $\left(1.775 \mathrm{~km}^{2}\right)$ respecto de Valencia $\left(134.6 \mathrm{~km}^{2}\right)$, no permite realizar un comentario tan exhaustivo de las sendas más identificadas por la población escolar. El uso diario que otorga el alumnado a las vías que han nombrado como más importantes (Avenida Carrera Séptima, Avenida NQS, Avenida Caracas y la Vía del Ferrocarril) tiene una trascendencia mayor al significado proporcionado. Se trata de grandes vías que permiten conectar el espacio urbano de Bogotá de norte a sur, por lo que dada la magnitud de las mismas nos permite afirmar que algunos de sus tramos son espacios percibidos o concebidos para la población escolar, pues no son usualmente frecuentados en su desplazamiento cotidiano. La representación hegemónica de estas sendas apunta al excesivo tráfico y puntualmente han nombrado algunas edificaciones residenciales notorias por ubicarse en las laderas que flanquean estas avenidas. La percepción de esas sendas la han complementado con referencias a centros comerciales y el parque de Altablanca. Sobre este último espacio de ocio han mencionado que es "un lugar seguro" y “donde podemos jugar a fútbol”, si bien es cierto que los parques no suelen ser espacios de gran confianza para la población colombiana ni dentro ni fuera de sus barrios de residencia.

Sin abandonar el mismo barrio de Altablanca, el alumnado ha mostrado su sentimiento de inseguridad, rechazo y desconfianza hacia ciertas calles y espacio públicos que hemos clasificado como bordes. A diferencia de las grandes avenidas anteriores, ahora son calles secundarias, más estrechas y peor comunicadas que aunque forman parte de su espacio vivido, suelen evitar frecuentar en momentos puntuales como al anochecer. Los espacios públicos son especialmente parques (Parque de las Rampas, el Parque del Ahorcado y el Parque "El Pañuelito") que son 
percibidos mayoritariamente como lugares inseguros debido a que los grupos sociales que los frecuentan consumen alcohol, tabaco y drogas. Algunas expresiones lo revelan diciendo que "hay malandros", "meten marihuana" y "se encuentran personas ñeras que fuman y beben". Tanto las calles estrechas como estos parques son lugares que evitan en sus desplazamientos cotidianos ante el miedo a ser atacados o atracados.

Fuera del barrio de Altablanca, la representación social de otros lugares ajenos a su espacio más inmediato coincide con clasificaciones teóricas basadas en criterios sociales y económicos que afectan a la calidad de vida de sus habitantes. De las veinte localidades existentes en la ciudad de Bogotá, la representación escolar designa a Usaquén como una de las zonas de mayor desarrollo económico y, por consiguiente, la que proporciona mayor agrado y satisfacción para el alumnado. Es un espacio que cuenta con urbanizaciones y tres centros comerciales, además de otros tres centros universitarios y óptimas comunicaciones en sentido radial con barrios colindantes. La reconversión económica desde sectores agrícolas a un predominio de servicios explica que esta localidad se encuentre en un estrato cinco (medio alto) generalizado. Por extensión de estas condiciones, el centro histórico de la localidad vecina de Santafé es percibido como un espacio agradable por el alumnado bogotano debido a la oferta cultural (museos. monumentos, teatros...) que presenta a un público diverso.

A medio camino entre estos lugares agradables y los menos apetecibles para la población escolar, se encuentra la localidad de Usme. Por estar más alejada y separada del casco urbano de Bogotá, y contar con predominio de grandes extensiones de cultivos, la asemejan más a un espacio natural que social. En el lado menos agradable encontramos las localidades de Ciudad Bolívar y Kennedy. La percepción como lugares inseguros y con presencia de actos delictivos, que históricamente se asocian a luchas por la propiedad de la tierra y el derecho a la vivienda (caso de Ciudad Bolívar) o por los ataques y robos en comercios y servicios en la ciudad de Kennedy, se ha mencionado más como una percepción generalizada en la opinión pública que como una vivencia directa por el alumnado. Estas visiones estereotipadas y más generalizadas se han contrastado parcialmente en sentido opuesto con las experiencias de vida de algunos alumnos/as que frecuentan estas localidades asiduamente.

En cuanto a los nodos más representativos son ubicados por los estudiantes en el extremo oriental de la ciudad de Bogotá: el Santuario de Monserrate y el Nort Point. La ubicación periférica es el único elemento común a estos dos lugares que son frecuentados por los estudiantes, amistades y familiares en tiempo de ocio. El Santuario de peregrinación de Monserrate está emplazado en un cerro homónimo de fácil acceso a pie o por funicular, y que oferta visitas todos los días de la semana en un horario bastante amplio que se extiende a festivos. Por ello, la mayoría lo han mencionado como "un lugar religioso", “donde van muchos turistas” y “donde se puede estar con la familia”. Por su parte, el Nort Point es un complejo de edificios cuyo espacio ha sido rehabilitado de antiguas canteras mediante la plantación y la siembra de espacios verdes para albergar edificios residenciales, espacios de ocio (centros comerciales) y sedes de empresas financieras. Para el alumnado es un nodo local de reconocido prestigio que actúa como punto de referencia en tanto que es un espacio de tránsito diario, aunque la mayoría desconoce las redes económicas y empresariales que se están tejiendo dentro de ese complejo en expansión.

A menor escala se presentan otros nodos como parques, edificios y lugares culturales y algunos centros comerciales. Los parques son de menor tamaño que los que hemos señalado como espacios complementarios a las sendas. Ahora se trata de parques para disfrutar con la familia y las amistades, como los de Salitre Mágico y Mundo Aventura (parques de diversiones o atracciones). El Parque Simón Bolívar es concebido como un nodo local que aglutina a buena parte de la población bogotana porque ofrece actividades culturales y actuaciones al aire libre, lo que refuerza el sentimiento de seguridad por algunos estudiantes que afirman que "se puede pasear en familia". Después de estos parques, el alumnado ha citado como menos relevantes los museos y plazas del 
centro histórico al sentirse parcialmente atraídos por su oferta cultural y esporádicamente han señalado algunos centros comerciales a los que acuden en busca de actividades de ocio.

La última categoría que presentamos son los hitos urbanos, cuyas percepciones hemos agrupado en cuatro categorías excluyentes. Primero tenemos los lugares de esparcimiento que han sido valorados por la oferta de infraestructuras (pistas de fútbol, canchas de baloncesto...) y la seguridad que ofrecen cuando practican algún deporte. Así ha sido representado el parque de Altablanca porque "pueden hacer deporte" y "porque es un parque seguro". Como complejo deportivo se ha nombrado el estadio de fútbol Nemesio Camacho "El Campín”, por el ambiente de jolgorio que se crea cuando se celebran competiciones deportivas, aunque no sea un espacio regularmente frecuentado por el alumnado al estar separado por 13 kilómetros respecto del centro escolar. Segundo, los hitos de servicios son fundamentalmente supermercados y otros comercios de pequeña escala como papelerías y panaderías. El alumnado valora las papelerías "porque allí compramos los materiales para el colegio" y las panaderías "porque siempre hay pan caliente”. En tercer lugar, las iglesias son apreciadas por ser un punto de referencia y de socialización al que el alumnado acude regularmente. En último término se encuentran los centros escolares, lo cual choca con la representación positiva del centro encuestado como un lugar agradable. Los espacios educativos son nombrados por favorecer situaciones afectivas (se reúnen con familiares y amistades cuando acuden a estudiar) o por las imágenes que se proyectan de algunos grupos específicos. Como ejemplo, han afirmado que sobre el Colegio Divino Maestro "hay mucho ñero".

En cualquier caso, la representación escolar del espacio urbano de Bogotá es dual en cuanto a algunos elementos como los parques. Aunque suelen ser espacios destinados al ocio, incluso se perciben como lugares agradables por la oferta deportiva y recreativa que poseen, otro grupo de estudiantes los cataloga como desagradables debido a la inseguridad que acarrean situaciones de consumo de sustancias psicoactivas. No podemos afirmar que sean situaciones continuadas, más bien ocurren en diferentes horas del día y se concentran en lugares y sectores específicos de la población. Esta misma representación social dual es extensible a grupos sociales de edades adultas (Torres Pérez, 2013).

\section{DisCUSIONES}

El alumnado ha respondido en función de las percepciones que elabora en su vida cotidiana, destacándose los aspectos más evidentes que experimenta en su entorno inmediato, que generalmente se corresponde con su barrio de residencia. Los elementos morfológicos (sendas, bordes, nodos e hitos urbanos) pueden ser comparados y discutidos para abordar algunos rasgos característicos de las representaciones sociales de la ciudad global. Esto es así porque estamos interesados en conocer la comprensión geográfica del espacio urbano desde la dimensión subjetiva, pues el espacio se compone de concepciones, representaciones y vivencias de acuerdo a lo que se trabaja desde la geografía de la percepción y del comportamiento (Araya, Souto y Herrera, 2015).

Una primera diferencia estriba entre la valoración de las sendas de ambas ciudades. En la ciudad de Valencia cuentan con una connotación positiva por cuanto vinculan espacios naturales (Jardín del Turia) y la vida en espacios culturales (Ruzafa, Cánovas...) que favorecen la socialización. Sin embargo, las dificultades de movilidad urbana generan una representación negativa de las principales arterias urbanas bogotanas, a las que se asocia el tráfico y problemas de contaminación. Las visiones negativas se asemejan cuando se aborda la representación de los bordes, aunque existen algunas diferencias. En la ciudad de Valencia, las visiones negativas de la zona comprendida entre la Avenida de la Plata y Zapadores, junto con la peligrosidad asociada al barrio de Cabanyal tiene que ver con la carga ideológica que emana de la opinión pública. En el caso de Bogotá son las experiencias directas las que restringen el acercamiento a ciertos parques (Las Rampas, El Ahorcado...) por el desarrollo de actividades inseguras (alcoholismo, drogadicción). 
En cuanto a los nodos urbanos, la diferencia más notable estriba en la tipología de estos espacios. El Jardín del Turia es el elemento más valorado en Valencia frente al Santuario de Monserrate en Bogotá. El único aspecto común es el disfrute de condiciones naturales, lo que explica parcialmente que los siguientes nodos cuenten con peores condiciones: los parques urbanos de menor rango en Valencia (Parque de Colores, Mortadelo y Filemón...) requieren mejoras en su mantenimiento, mientras que en Bogotá la percepción dicotómica de algunos parques se inclina hacia el rechazo a frecuentar estos espacios públicos. En consecuencia, el alumnado suele reunirse en otros espacios más seguros: el entorno del campo de fútbol de Mestalla, Tarongers y la parte sur de Quatre Carreres (parque de bomberos, biblioteca...) en Valencia, y el complejo del Nort Point y el propio centro de la ciudad de Bogotá. En este sentido la oferta cultural de Valencia (Catedral, Torres de Serrano...) no ha sido tan valorada como el casco urbano de Bogotá.

Con estas interpretaciones podemos establecer unas categorías que relacionan la comprensión del espacio urbano en términos subjetivos (espacio absoluto, espacio relativo y espacio relacional) con la triple concepción que establece la geografía de la percepción y del comportamiento (Cuadro I). Valencia se presta a una mayor normalidad en los desplazamientos y en el establecimiento de relaciones sociales entre los estudiantes, mientras que en Bogotá la longitud de las principales vías de comunicación y los problemas de tráfico provoca que los desplazamientos sean más lentos y los espacios de socialización se reduzcan a centros religiosos y los parques más seguros. Pero ese mismo factor negativo de movilidad no impide que el alumnado bogotano se desplace fuera de su barrio de residencia, un aspecto que no es tan habitual entre los estudiantes de Valencia, a pesar de que no perciben obstáculos inmateriales a escala de ciudad. El Jardín del Turia es una barrera física que separa al alumnado de ambos centros, mientras que en Bogotá la delimitación de los barrios no impide desplazarse a zonas de ocio y recreo, generalmente más seguras que las de origen. Esto hace que el alumnado bogotano busque condiciones más seguras fuera de su barrio o concentre sus actividades de ocio en espacios públicos donde no son habituales las situaciones de delincuencia, tales como santuarios, iglesias o algunos complejos deportivos. El disfrute de condiciones naturales y de relajación en el Jardín del Turia lleva al alumnado de Valencia a idealizar ciertas situaciones cotidianas propias de su práctica espacial en detrimento de rememorar el valor patrimonial del propio casco antiguo y los edificios más representativos que lo componen.

CUADRo 1. Síntesis de las categorías de análisis entre Valencia y Bogotá

\begin{tabular}{|c|c|c|c|c|c|c|}
\hline & \multicolumn{2}{|c|}{ Espacio percibido } & \multicolumn{2}{|c|}{ Espacio concebido } & \multicolumn{2}{|c|}{ Espacio vivido } \\
\hline & Valencia & Bogotá & Valencia & Bogotá & Valencia & Bogotá \\
\hline \multirow[t]{2}{*}{$\begin{array}{l}\text { Espacio } \\
\text { absoluto }\end{array}$} & $\begin{array}{l}\text { Avenidas, calles } \\
\text { y barrios como }\end{array}$ & $\begin{array}{l}\text { Avenidas } \\
\text { grandes y calles }\end{array}$ & $\begin{array}{l}\text { No existen límites } \\
\text { perceptivos entre }\end{array}$ & $\begin{array}{l}\text { Conciencia de } \\
\text { límites }\end{array}$ & $\begin{array}{ll}\text { Disfrute } & \text { de } \\
\text { espacios }\end{array}$ & $\begin{array}{l}\text { Inseguridad } \\
\text { en algunos }\end{array}$ \\
\hline & $\begin{array}{l}\text { espacios } \\
\text { abiertos }\end{array}$ & $\begin{array}{l}\text { estrechas } \\
\text { inseguras }\end{array}$ & barrios & $\begin{array}{l}\text { jurisdiccionales } \\
\text { entre barrios }\end{array}$ & $\begin{array}{l}\text { naturales } \\
\text { culturales }\end{array}$ & $\begin{array}{l}\text { parques } \quad \mathrm{y} \\
\text { calles }\end{array}$ \\
\hline $\begin{array}{l}\text { Espacio } \\
\text { relativo }\end{array}$ & $\begin{array}{l}\text { Rapidez en los } \\
\text { desplazamientos }\end{array}$ & $\begin{array}{l}\text { Lentitud en los } \\
\text { desplazamientos }\end{array}$ & $\begin{array}{l}\text { Desplazamientos } \\
\text { dentro del barrio }\end{array}$ & $\begin{array}{l}\text { Desplazamientos } \\
\text { entre barrios }\end{array}$ & $\begin{array}{l}\text { Tranquilidad en } \\
\text { la mayoría de } \\
\text { desplazamientos }\end{array}$ & $\begin{array}{l}\text { Incomodidad } \\
\text { en la mayoría } \\
\text { de } \\
\text { desplazamien- } \\
\text { tos }\end{array}$ \\
\hline $\begin{array}{l}\text { Espacio } \\
\text { relacional }\end{array}$ & $\begin{array}{l}\text { Fluidez en las } \\
\text { relaciones } \\
\text { sociales en } \\
\text { cualquier } \\
\text { espacio público }\end{array}$ & \begin{tabular}{l}
\multicolumn{3}{l}{ Concentración } \\
de relaciones \\
fluidas en \\
santuarios y \\
algunos parques
\end{tabular} & $\begin{array}{l}\text { Mejoras puntuales } \\
\text { en infraestructuras }\end{array}$ & $\begin{array}{l}\text { Mejoras } \\
\text { generalizadas en } \\
\text { infraestructuras }\end{array}$ & $\begin{array}{l}\text { Relajación en } \\
\text { espacios } \\
\text { abiertos (Jardín } \\
\text { del Turia) }\end{array}$ & $\begin{array}{l}\text { Topofobia en } \\
\text { determinados } \\
\text { parques por } \\
\text { problemas } \\
\text { (alcoholismo, } \\
\text { drogadicción). }\end{array}$ \\
\hline
\end{tabular}

Fuente: Elaboración propia

Consecuentemente podemos decir que la percepción intuitiva del espacio urbano condiciona el aprendizaje de la ciudad global, ya que algunos aspectos como la movilidad, las relaciones sociales y el apego por algunos lugares concretos presenta valoraciones diferentes entre una y otra 
ciudad. Por ello necesitamos establecer criterios para adquirir conceptos y habilidades que expliquen la experiencia directa e indirecta del alumnado en la formación de la representación social del espacio urbano. Esto se relaciona con la comprensión del espacio geográfico como un conjunto indisociable de objetos naturales y sociales (forma) y la sociedad (contenido) que establece el geógrafo Milton Santos. De esta manera se viene plasmando en los materiales didácticos del proyecto Gea Clío y en el grupo Geopaideia (Moreno y Cely, 2010), coincidiendo en un aprendizaje del espacio geográfico que parte de las vivencias del alumnado, pues dichas vivencias son un componente primordial en el análisis de la complejidad espacial como hemos mostrado entre las ciudades de Valencia y Bogotá.

\section{CONCLUSIONES}

El conocimiento que tienen los estudiantes de Educación Secundaria sobre el espacio urbano en las ciudades de Valencia y Bogotá parte de su conocimiento cotidiano y de sentido común que influye directamente en los comportamientos espaciales. Así se entiende que la construcción del conocimiento es un hecho complejo determinado por las relaciones sociales y culturales que influyen en la práctica, los códigos y los valores espaciales que constituyen las representaciones sociales. De este modo, la vinculación entre la teoría de las representaciones sociales y la geografía de la percepción y del comportamiento nos ha permitido conocer cómo se integran las concepciones del alumnado acerca del espacio urbano en el "sentido común social" que delimita sus conocimientos de forma inconsciente. Esto significa que una parte del alumnado del distrito de Algirós no frecuenta asiduamente el distrito de Quatre Carreres porque el pensamiento de sentido común identifica el segundo espacio con la percepción de ciertos grupos étnicos de la Avenida de la Plata. En el caso de Bogotá, el alumnado no visita el parque de El Pañuelito aunque el alcoholismo y la drogadicción no sean problemas que ocurran regularmente en esos espacios públicos, más bien han sido percibidos en ciertos momentos por algunas personas adultas.

Los resultados revelan que la percepción del alumnado es un componente que nos permite graduar los aprendizajes sobre el espacio urbano. En el contexto de la ciudad global, la primera aproximación al conocimiento espacial de los estudiantes es de tipo incidental; sin embargo, hemos descubierto que se enmascaran aspectos subjetivos relevantes en la planificación de intervenciones didácticas. En este sentido, coincidimos con González y García Pérez (2014) que los procesos de aprendizaje y enseñanza de la ciudad tienen que considerar estos espacios como un sistema en el que se conjugan la escala local y la global en un sentido bidireccional, ya que de esta forma se podrá trabajar la ciudad desde la categoría barrio y conocer las problemáticas que afectan a la ciudadanía. Han aparecido referencias sobre problemas como la inseguridad y la pobreza que son descritos a escala local (barrio) pero son consustanciales a la comprensión de la ciudad global. La percepción de las dos ciudades como espacios públicos ha sido más sucinta, pero a escala de barrio se han mostrado unas relaciones e interacciones más intensas que generan identidad y afectan a la ciudadanía global.

En síntesis podemos afirmar que la aproximación al conocimiento de las representaciones sociales de la ciudad global a partir de dos espacios urbanos diferenciados se puede convertir en contenidos educativos que con un adecuado método de trabajo contribuirán a mejorar la participación pública del alumnado en asuntos urbanos. Esto nos tiene que llevar a reflexionar sobre el fomento de habilidades propias del pensamiento geográfico que faciliten la representación del espacio y el desarrollo del pensamiento crítico porque las ciudades globales son un escenario de aprendizaje para el alumnado y el ámbito en el que desarrollarán su proyecto de vida. 


\section{Referencias}

Araya, F., Souto, X.M., y Herrera, Y. (2015). El espacio geográfico, una construcción escolar. Un estudio de caso: los alumnos del valle del Limarí (Chile). Scripta Nova, Revista Electrónica de Geografía y Ciencias Sociales, XIX(503).

Boira, J.V., Reques, P. y Souto, X.M. (1994). Espacio subjetivo y Geografía, Orientación teórica y praxis didáctica. Valencia: Ediciones Nau Llibres.

Capel, H. (1973). Percepción del medio y comportamiento geográfico. Revista de Geografía, 1-2, 58-150.

Castro, C. de (1997). La búsqueda de datos para mapas cognitivos. Anales de Geografía de la Universidad Complutense, 17, 27-38.

Fernández Gutiérrez, F. y Asenjo Pelegrina, R. (1998). La visión subjetiva del espacio urbano almeriense. Almería: Instituto de Estudios Almerienses.

González, J.F. y García Pérez, F.F. (2014). Las concepciones de los alumnos sobre el medio urbano y sus implicaciones didácticas. Un estudio en Bogotá. Didáctica Geográfica, 15, 41-60.

Lynch, K. (2000). La imagen de la ciudad. Barcelona: Editorial Gustavo Gili.

Morales Yago, F.J. (2015). La ciudad de Valencia como espacio percibido por los estudiantes universitarios. Aportaciones desde el análisis propuesto por la geografía de la percepción. Estudios Geográficos, 76 (278), 203-233. DOI: 10.3989/estgeogr.201507

Moreno, N. y Cely, A. (2010). Cotidianidad y enseñanza geográfica. Uni-pluri/versidad, Vol.10. 3. Versión digital.

Moscovici, S. (1979). El psicoanálisis, su imagen y su público. Buenos Aires: Huemul.

Rodríguez de Moreno, A. (2000). Geografía conceptual, Enseñanza y aprendizaje de la geografía en educación básica primaria. Bogotá: Tercer Mundo Editores.

Sammut, G., Andreouli, E., Gaskell, G. y Valsiner, J. (2015). Social representations: a revolutionary paradigm? En G. Sammut, E. Andreouli, G. Gaskell y J. Valsiner (Eds.), Cambridge Handbook of Social Representations (pp. 3-11). Cambridge: Cambridge University Press.

Sassen, S. (1991). The Global City. New York, London, Tokyo. Princeton-New Jersey: Princeton University Press.

Souto, X.M. (1998). Didáctica de la Geografía. Problemas sociales y conocimiento del medio. Barcelona: Ediciones del Serbal.

Torres Pérez, L. (2013) La alfabetización de la ciudad, un aporte a la apropiación del medio urbano. Trabajo de maestría inédito. Bogotá: Universidad Sergio Arboleda.

Vara, J. L. (2008). Cinco décadas de Geografía de la percepción. Revista Ería, 77, 371-384. DOI: $\underline{10.17811 / \mathrm{er} .0 .2008 .371-384}$

CÓMO CITAR ESTE ARTÍ́CULO

García Monteagudo, D. y Torres Pérez, L. G. (2018). Pensar la ciudad global desde sus representaciones escolares: un estudio de caso entre Valencia (España) y Bogotá (Colombia). Didáctica de las ciencias experimentales y sociales, 34, 49-62. DOI: 10.7203/DCES.34.12182. 


\section{Anexos}

$\underline{\text { Anexo I. Primera parte de la encuesta }}$

\begin{tabular}{|c|c|c|}
\hline \multirow{2}{*}{ (ON) } & \multirow{2}{*}{$\begin{array}{l}\text { WNIVERSITAT } \\
\text { D VALENCIA }\end{array}$} & Proyecto: La semitiótica del espacio. \\
\hline & & Instrumento No. 1: Juan llega a la ciudad \\
\hline
\end{tabular}

1. Juan acaba de llegar a la ciudad de Valencia y ha entrado a estudiar a tu curso, Juan quiere saber:

- Nombre del Instituto: Raman Lluli

- $\quad$ Curso en el que se encuentra: $3^{3} \in S O$

- Barrio donde se encuentra en el instituto:

- Edad que tienes: 16 años

- Lugar donde naciste: Colombia cali

- Tiempo que llevas viviendo en Valencia: 10 añes

2. Juan quiere saber qué lugares te son agradables en el instituto, cuáles no lo son y por qué. Contesta en la tabla.

\begin{tabular}{|l|l|}
\hline Lugares Agradables & Porque... \\
\hline Patio & Mi mumento lifore \\
\hline Clase de musica & Porque me gusta mucho la musica \\
\hline & \\
\hline Lugares desagradables & Porque... \\
\hline La zona donde fuman & Porquer mer ces desaguadable \\
\hline & \\
\hline & \\
\hline
\end{tabular}

3. Juan llegó a vivir al barrio Algirós. De su casa al instituto lo han traido en coche y ha visto varios lugares, entre ellos la calzada del tranvia y la Universidad de Valencia.

- ¿En qué barrio vives tu? Mavitin

- ¿En qué medio de transporte llegas hasta el instituto? Bicicleta

- ¿Qué lugares son representativos en el trayecto de tu casa al instituto? Polide portivos, las universidades

4. Juan quiere conocer tu barrio, ¿qué lugares le recomendarias visitar? ¿cuáles no? ¿por qué? Contesta en la tabla.

\begin{tabular}{|c|l|}
\hline Lugares que recomiendas & Porque... \\
\hline Playa & Porque to pucdes refrescar \\
\hline Las canchay & puerdes jugar $x$ hacer deporta \\
\hline & \\
\hline
\end{tabular}


$\underline{\text { Anexo II. Lugares preferenciales (ejemplo por alumno del IES Ramón Llull) }}$
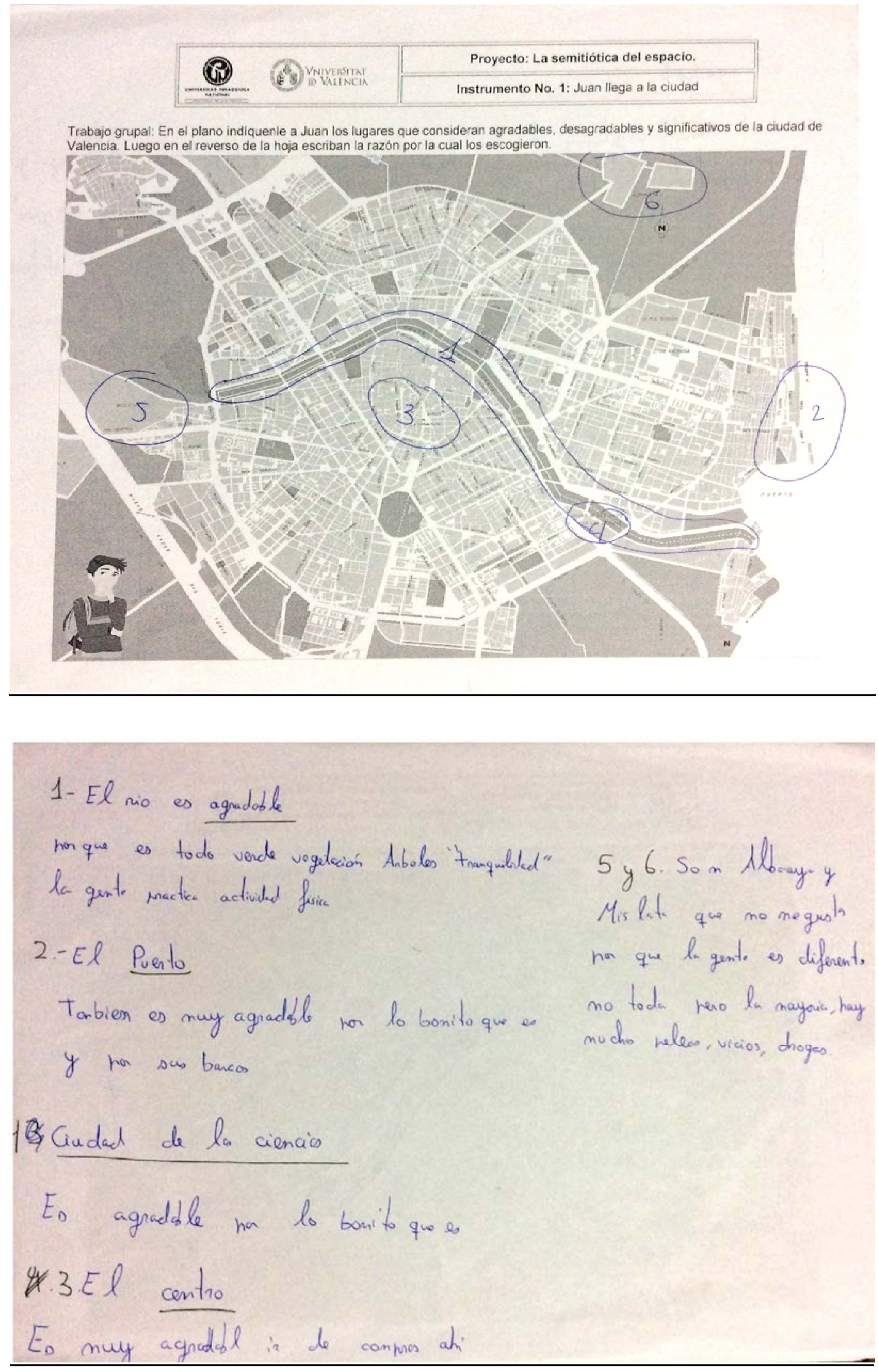